\title{
Ground-based radar observations of snow stratigraphy and melt processes in the percolation facies of the Greenland ice sheet
}

\author{
I. H. H. Zabel, K. C. JezeK, P. A. Baggeroer, \\ Byrd Polar Research Center, The Ohio State University, Columbus, OH 43210, U.S.A. \\ S. P. Gogineni \\ Radar Systems and Remote Sensing Laboratory, The University of Kansas, Lawrence, KS 66045, U.S.A.
}

\begin{abstract}
Summer melt is a primary source of mass loss on the Greenland ice sheet. An understanding of melt processes on the ice sheet, their connection with atmospheric processes, and the redistribution of meltwater is important for ascertaining the mass balance of the ice sheet. High-resolution radar measurements made in the percolation zone of the Greenland ice sheet reveal the evolving radar signature of summer surface melting and subsequent refreezing of meltwater. A traverse over the snow surface has resulted in the first radar map of snow stratigraphy over an extended distance. The dominant sources of back-scatter in the study area are the snow surface and effectively continuous annual ice layers. We suggest applications of our results to help define the extent of the percolation zone and to discriminate between regions where surface melt is lost to the sea and those where melt refreezes nearly in place.
\end{abstract}

\section{INTRODUCTION}

Mass wastage from the Greenland ice sheet is determined largely by the vigor of summer melt. Melt is controlled by the surface energy balance and can be amplified by changes in snow albedo, which decreases by $\sim 20 \%$ as the snow becomes wet (Steffen and others, 1993). Runoff of meltwater is the major source of mass loss on the Greenland ice sheet, but not all surface melting represents mass loss (Pfeffer and others, 1991). Thus, an understanding of melt processes on the ice sheet, their connection with atmospheric processes, and the final destination of the meltwater is important for ascertaining the mass balance of the ice sheet.

Microwave remote sensing from space allows coverage of large areas, penetration through cloud cover, and night-time operation, and so is an excellent tool for observing the world's great ice sheets (Fahnestock and others, 1993; Goldstein and others, 1993). Recently, several researchers have focused their attention on monitoring possible shifts in the melt zones (Benson, 1962) of the Greenland ice sheet with spaceborne radar, as indicators of mass-balance changes (Fahnestock and Bindschadler, 1993; Fahnestock and others, 1993).

In order to interpret radar images of ice sheets, one must understand the scattering mechanisms of the nearsurface. In the percolation zone of the Greenland ice sheet, large, near-surface ice pipes, lenses and layers formed from downward percolation and refreezing of summer meltwater act as strong microwave scatterers (Swift, 1985; Rignot and others, 1993). During field experiments in the percolation zone, Jezek and others (1994) demonstrated that the 5.3 and $13.5 \mathrm{GHz}$ radar returns at Crawford Point $\left(70^{\circ} \mathrm{N}, 47^{\circ} \mathrm{W}\right)$ were dominated by scattering from a layered, icy zone marking the previous summer's melt.

Questions about these ice layers and inclusions and their scattering properties remain, however, which, if answered, would help us use airborne and spaceborne remote sensing to study the interaction of ice sheets and climate. For instance, Benson (1962) notes that the "interpretation of firn strata is based more on similar layered sequences than on positive identifications of a specific layer." For interpreting remotely sensed scattering data, however, one would like to know whether the strong scattering identified by Jezek and others (1994) as coming from a depth where ice layers were observed behaves like scattering from a specific continuous layer or scattering from localized ice structures. This knowledge is particularly important for applications of radar altimetry to monitoring changes in ice-sheet elevation and characteristics (Ferraro, 1994). In addition, one would like to quantify the temporal variability in back-scatter from a region such as the percolation zone in the summer, when temperatures are often close to $0^{\circ} \mathrm{C}$. Under these conditions, one would expect small temperature changes to lead to large variations in both the passive 
and active microwave response because of the sensitivity of microwave scattering to free water.

Using a high-resolution radar, we have produced the first radar map of sub-surface ice structures in the percolation zone over an extended distance. With our technique we are able to learn about the physical characteristics and extent of ice layers in a fashion previously unachievable using conventional techniques. In addition, the high-resolution radar has enabled us to observe water-redistribution processes in the percolation zone. Here, we describe our radar system and snow studies, and we present interpretations of a time series of radar observations at a site as temperatures decreased, and of a transect of radar back-scatter from the snow.

\section{SNOW-PIT STUDIES}

From 18 June to 12 July 1993 , we measured snow radar back-scatter and physical properties at a site on the Greenland ice sheet (Fig. 1), near Dye-2 $\left(66.5^{\circ} \mathrm{N}\right.$, $\left.46.3^{\circ} \mathrm{W}\right)$. We used shallow $(2 \mathrm{~m})$ pit excavations as diagnostic tools in determining the physical properties and stratigraphic characteristics of areas in which we made radar measurements, as well as surrounding areas.

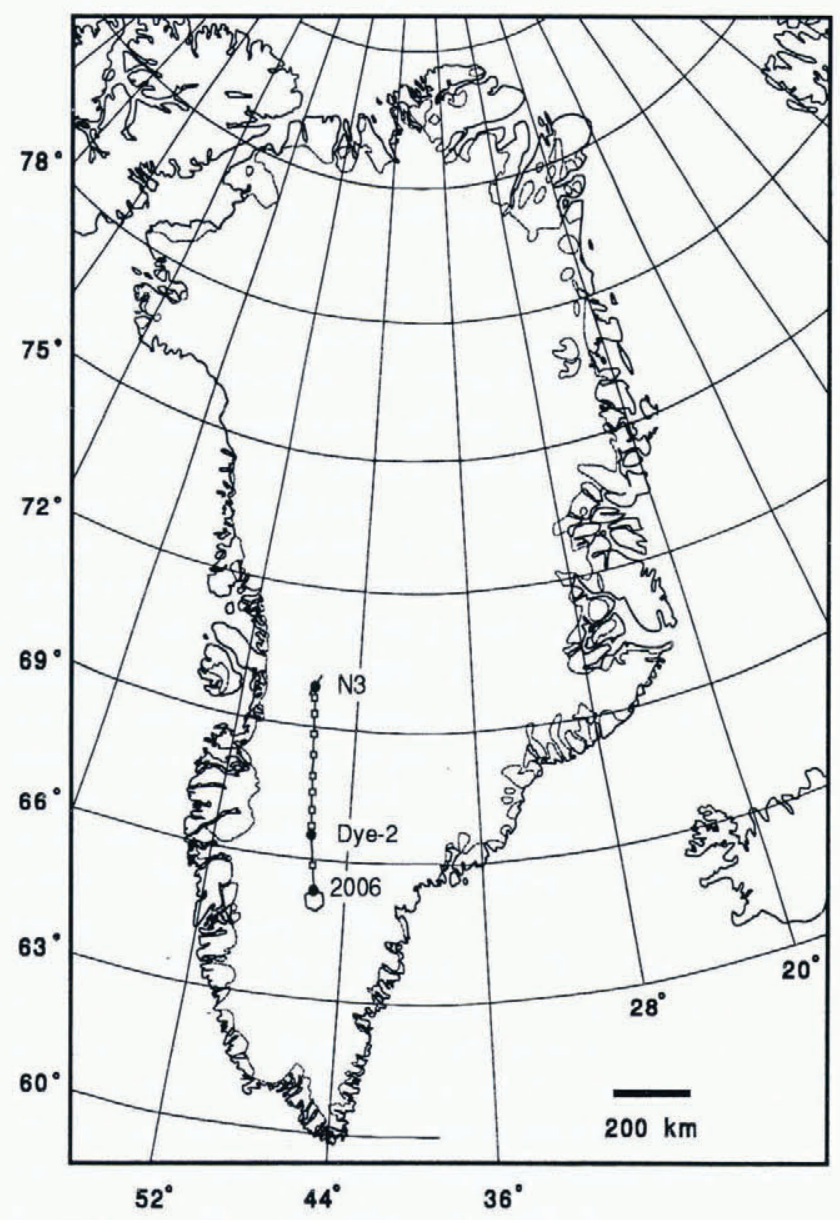

Fig. 1. Map of Greenland, showing Crawford Point (labeled "N3"), Dye-2 and sites of pits (open squares) along the route in between.
Pit walls were characterized by density, temperature, snow wetness and grain-size as a function of depth. Figure 2 shows results typical of the pits we studied. Of particular interest in our radar studies, we noted thick ice layers ( $\sim 2-3 \mathrm{~cm}$ thick), often layered with large ice grains, at depths of $85-105 \mathrm{~cm}$ below the surface of all pits in the Dye-2 area. At depths of $180-220 \mathrm{~cm}$ we also found hard, icy layers mixed with regions of large, fused ice grains. These layers near 1 and $2 \mathrm{~m}$ depths correspond to the seasonal melts of 1992 and 1991, respectively.

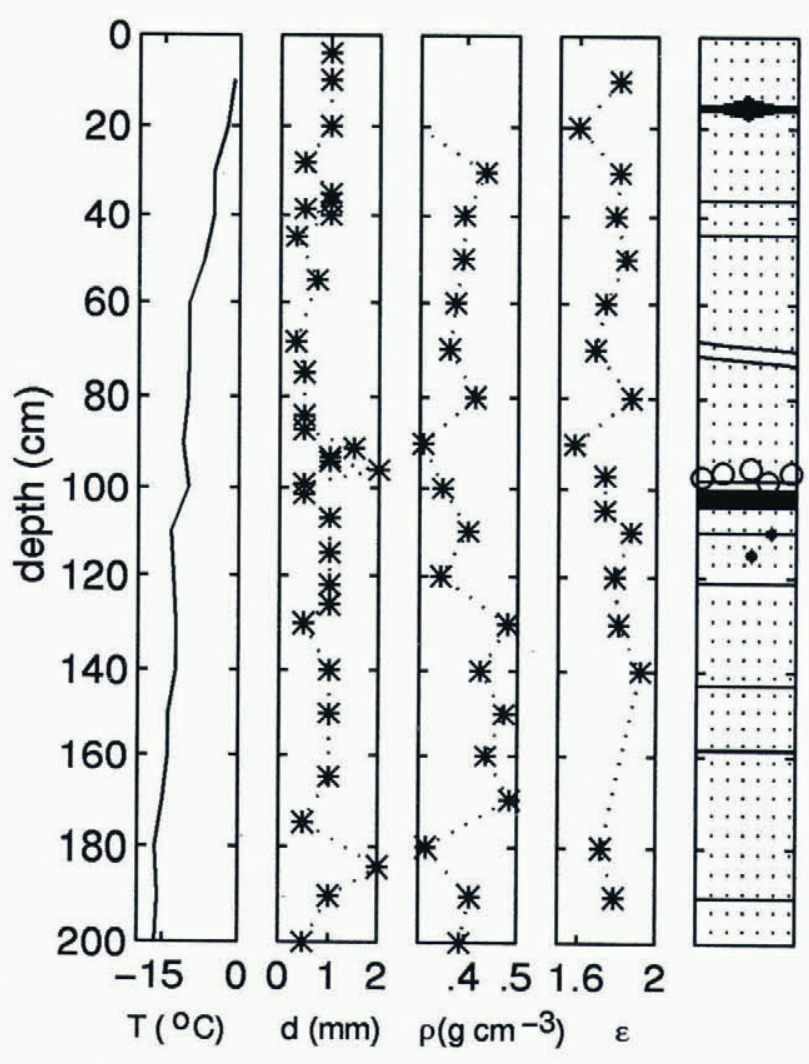

Fig. 2. Example of physical-properties data collected from a $2 \mathrm{~m}$ deep pit on 25 June 1993. Shown versus depth are temperalure $T\left({ }^{\circ} \mathrm{C}\right)$, maximum ice-grain diameler $d$ $(\mathrm{mm})$, snow density $\rho\left(\mathrm{g} \mathrm{cm}^{-3}\right)$, real part of the dielectric constant at $20 \mathrm{MHz} \epsilon$, and stratigraphy. In the stratigraphy, black regions represent ice; large circles represent large grains.

In addition, we observed the formation of ice structures in the top $80 \mathrm{~cm}$ below the surface resulting from the current summer's melt. During the first few days of observations we saw very few ice inclusions in the top meter of snow, whereas by the end of our stay, which had included several warm periods, we found ice lenses and pipes in the pits we had dug. The lenses typically formed at a mechanical boundary such as a wind crust or a thin ( $1-2 \mathrm{~mm}$ thick) ice layer; they were typically of variable thickness and roughness, $1-2 \mathrm{~cm}$ thick vertically and $\sim 10-30 \mathrm{~cm}$ long horizontally. We observed ice pipes with vertical dimensions of $\sim 10$ $50 \mathrm{~cm}$ and horizontal dimensions of $\sim 2-9 \mathrm{~cm}$. Narrow pipes often widened just above a wind crust or thin ice 
layer, presumably due to pooling and subsequent refreezing of meltwater.

\section{EXTENDED-DISTANCE RADAR OBSERVATION OF SNOW STRATIGRAPHY}

One can extract valuable information about the local climate and the physical properties of the firn by digging a pit. A meter-wide pit, however, gives only a very localized picture of the overall structure of the snow. Unless one digs and correlates strata over many pits, a large ice lens spanning a pit wall might be misinterpreted as a layer that is continuous over long distances and representative of a seasonal event, although in reality the feature might terminate only a short distance away. With a highresolution radar which penetrates the snow, one is able to move along the surface and probe sub-surface glaciological structures and their continuity. Essentially, one can map the main features of near-surface firn stratigraphy over long distances (Davis and Poznyak, 1993).

On 9 July we made a $100 \mathrm{~m}$ traverse with a $13.5 \mathrm{GHz}$ radar, stopping every meter to take a measurement at normal incidence. We used an FMCW radar with a $2 \mathrm{GHz}$ bandwidth. This wide bandwidth allowed the radar to operate with a resolution in free space of about $15 \mathrm{~cm}$ (including windowing effects); in snow the resolution is even finer, about $11 \mathrm{~cm}$. Values of the volume back-scatter coefficient as a function of range are obtained by combining the radar equations for the actual target and for a calibration target. For calculation purposes, we assume a snow index of refraction $n=1.32$ (from an average of $2 \mathrm{~m}$ pit measurements).

The radar was mounted onto a sled so that the entire system was self-contained and mobile. The resulting 100 radar echoes are shown in Figure 3 as a function of range from the radar and distance across the ice sheet. The echoes have been multiplied by a gain function which increases linearly with range, in order to accentuate the returns at depth in the snow, which are weaker than those at or near the surface.

Inspection of Figure 3 shows strong returns from the snow surface at about $1.5 \mathrm{~m}$ from the radar, followed by another series of strong returns at nearly $1 \mathrm{~m}$ below the surface. We believe these returns correspond to the ubiquitous ice layer we observed around this depth in all the pits we dug, and in single-spot radar observations. Since we observed a return from near this depth at every spot we sampled, we conclude that the layer scatters as a continuous layer over long distances. Continuing down into the snowpack, we observed another layer of less continuously large radar returns which corresponds to ice formed after summer melting in 1991. At about $4 \mathrm{~m}$ range from the radar (i.e. $2.5 \mathrm{~m}$ depth below the snow surface), Figure 3 shows a sparse but noticeable layer of returns, presumably from another zone in the snow containing large ice structures. We have checked the travel times of the returns to make sure that what we interpret as real layers are not multiple reflections from other layers or from the snow surface.

Also apparent in Figure 3 are occasional strong returns from regions between the ice layers, e.g. between the snow surface and the first ice layer, at $\sim 30-40 \mathrm{~cm}$

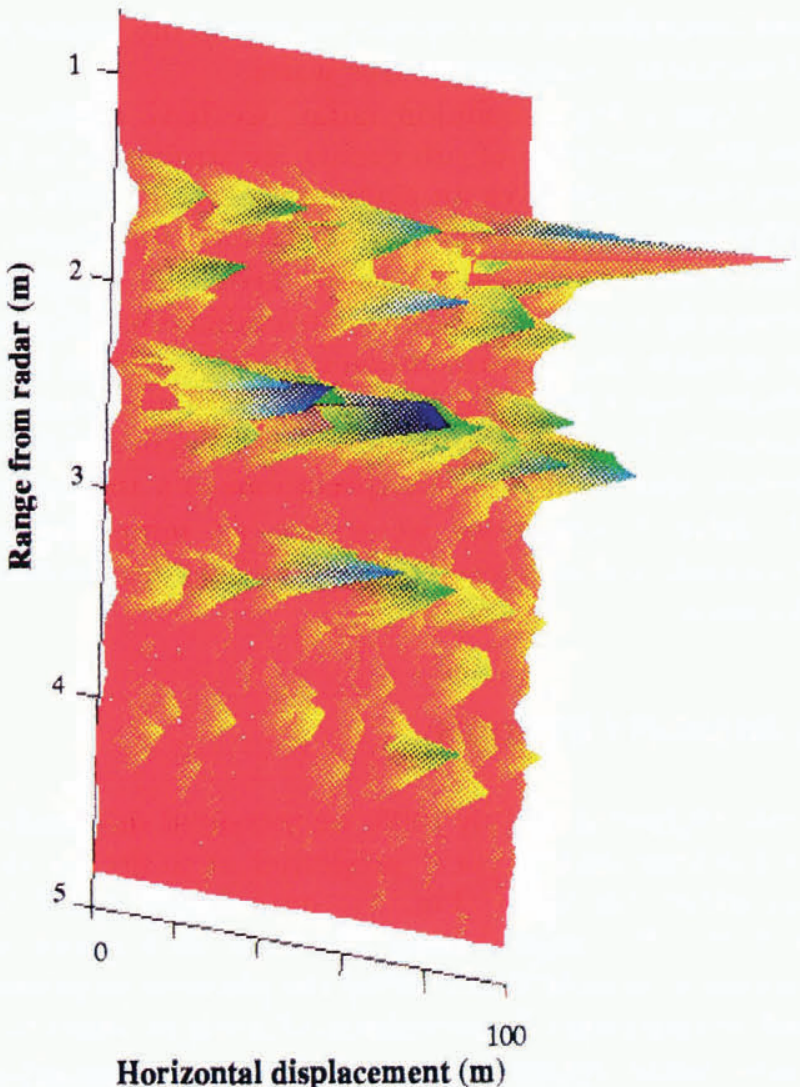

Horizontal displacement (m)

Fig. 3. Suite of normal-incidence radar echoes from a $100 \mathrm{~m}$ traverse. One sample was laken every meter. Returns are shown versus range from the radar and displacement across the snow surface; the range to the snow surface was approximately $1.5 \mathrm{~m}$.

below the snow surface, and between the second and third ice layers. Based on our pit observations, we interpret these returns as coming from ice lenses and/or pipes. Layers, however, rather than lenses or pipes, are the dominant feature of Figure 3, confirming the experimental conclusions reached by Jezek and others (1994).

We have extracted the two-way travel times for the snow surface and first ice layer, and find a strong degree of correlation between travel times across the $100 \mathrm{~m}$ length of the traverse. The snow-surface travel time was defined as the travel time for the first peak after $5 \mathrm{~ns}$; any peaks before this time were from antenna feed-through signals. The first ice-layer travel time was defined as the time corresponding to the largest peak between 15 and 20.52 ns. These bounds were determined from a composite plot of travel times for all 100 samples. For the snow surface, we find a mean travel time $\left\langle t_{\mathrm{s}}\right\rangle=8.85 \mathrm{~ns}$ and a variance in travel times $\sigma^{2}=0.46 \mathrm{~ns}$ (means are averages over 100 samples). For the first ice layer, we find similarly $\left\langle t_{\mathrm{i}}\right\rangle=17.3 \mathrm{~ns}$ and $\sigma^{2}=1.21 \mathrm{~ns}$. Part of the variance in travel times for both surfaces is a result of uncertainty in the incidence angle of the radar, which we suspect varied a few degrees around normal incidence from sample to sample. The larger variance of travel times for the ice layer compared to the snow surface may be indicative of horizontal variations in snow density, ice-lens and pipe density, and localized ice-layer tilt. An auto-correlation analysis of travel times shows strong lateral correlation for both the snow surface and the ice layer, however. The 
auto-correlation function for both time surfaces is a triangle wave, as would be expected from an input of a finite collection of returns at nearly the same time (i.e. a square wave).

\section{RADAR OBSERVATIONS OF MELT PROGESSES}

We were able to observe melting and refreezing events that lead to formation of ice layers with our radar as well as in pit studies. Figure 4 shows the VV-polarized radar returns vs range from the radar for the same site on four consecutive days, 23-26 June 1993. The returns are averaged over several spots at the site to reduce fading. The top row of Figure 4 shows normal-incidence returns; the following two rows show returns at $20^{\circ}$ and $40^{\circ}$ incidence from normal, respectively. At the bottom of Figure 4 is a record of air temperature at the site over the $4 \mathrm{~d}$ period. Note that the mean air temperature gets progressively colder from 23 June (maximum air temperature $\sim+1.5^{\circ} \mathrm{C}$ ) to 26 June (maximum air temperature $\sim-3^{\circ} \mathrm{C}$ ).

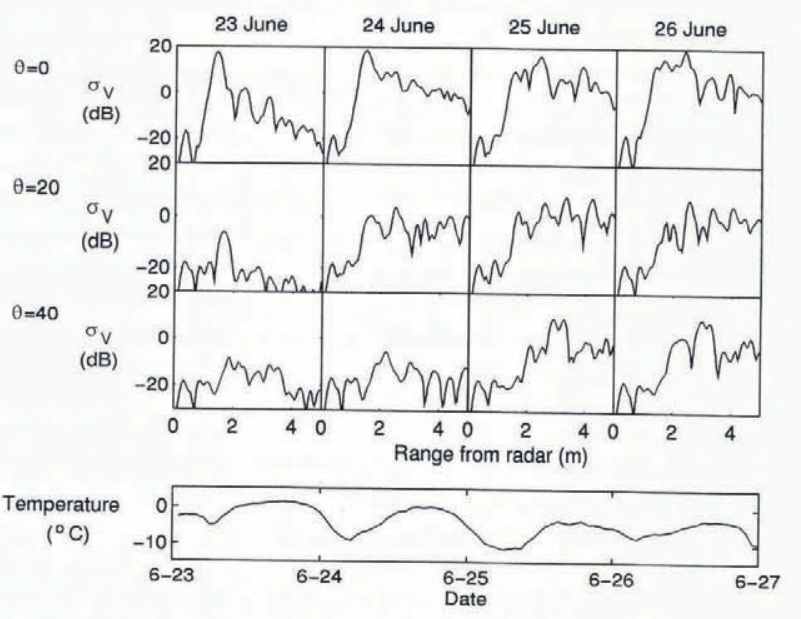

Fig. 4. VV-polarized radar returns at $13.5 \mathrm{GHz}$ for one site on four consecutive days. The top row shows normalincidence returns; the following two rows show returns at $20^{\circ}$ and $40^{\circ}$ incidence, respectively. The bottom of the figure shows air temperature vs time for the $4 d$.

Inspection of the normal-incidence return on 23 June shows three distinct peaks: a strong return from the snow surface $(\sim 1.5 \mathrm{~m}$ from the radar), followed by returns peaking at about 0.9 and $1.8 \mathrm{~m}$ below the snow surface. These two returns at depth correlate well with sequences of ice strata observed in pits, i.e. summer melt layers from 1992 and 1991. The dominance of the snow-surface return suggests that the snow surface was wet. Melting likely occurred due to the warm daytime temperatures, although we have no direct measurements of snow wetness on this day.

As several days pass and air temperatures decrease, the normal-incidence returns change dramatically. The returns broaden and show more structure in the top meter of snow, and the magnitudes of the returns from depth more nearly approach that of the surface return. We believe that these observations are the result of two effects. First, as the temperature decreases and the snow becomes drier, the radar beam is able to penetrate farther into the snow, leading to a relative increase in returns from depth. Secondly, and more interesting, we suggest that the broad peak observed on 26 June represents scattering from ice inclusions that had formed as meltwater several days earlier, percolated through the snow and refroze. Indeed, on 29 June we dug a pit directly below where we had made the radar measurements, and we found several ice pipes and lenses at depths of $\sim 14,32,43$ and $52 \mathrm{~cm}$, in addition to annual ice layers at $86-91$ and $210 \mathrm{~cm}$ depth.

The time series of returns at $20^{\circ}$ and $40^{\circ}$ incidence show similar effects. On 23 June the return from the snow surface is the dominant feature. As several days pass, returns from deeper into the snow contribute strongly. At $40^{\circ}$ incidence on 25 and 26 June, a very strong return appears below the surface. This may be due to an ice lens or pipe (or cluster of lenses and/or pipes) which formed from refreezing of percolated meltwater from 23 or 24 June.

A spaceborne sensor such as the ERS-1 SAR does not have the spatial resolution of our instrument and would sense a return effectively integrated over depth into the snow. In order to compare our results with ERS-1 backscatter coefficients, we compute a total equivalent backscatter coefficient $\sigma^{\circ}$ by assuming a return effectively coming from the surface, but with power integrated over the contributions at depth. The ERS-1 SAR operates at $5.3 \mathrm{GHz}$ whereas our radar operates at $13.5 \mathrm{GHz}$, so a comparison of absolute values of $\sigma^{\circ}$ is not possible. Previous work (Jezek, and others, 1994) has shown that in a different area of the percolation zone 13.5 and $5.3 \mathrm{GHz}$ back-scatter coefficients have a similar incidence-angle response and differ by only a few decibels at a given angle. One would expect higher back-scatter at $13.5 \mathrm{GHz}$, since a shorter wavelength leads to more scattering from large snow grains and the rough surfaces of the ice layers. Typical ERS- 1 derived values of $\sigma^{\circ}$ are around $-2 \mathrm{~dB}$ (at VV polarization, $23^{\circ}$ incidence) in the percolation zone. By comparison, we find, at $20^{\circ}$ incidence and $\mathrm{VV}$ polarization, $\sigma^{\circ}$ ranging from $10.7 \mathrm{~dB}$ on 23 June to values of 2.4 and $1.0 \mathrm{~dB}$ on 25 and 26 June (see Table 1). We believe that the very low total return on 23 June is a result of low penetration due to snow surface wetness.

Table 1. Total equivalent surface back-scatter coefficient $\sigma^{\circ}$ in $d B$ for three angles of incidence $\theta$ on four consecutive days

\begin{tabular}{lcrc}
\hline & \multicolumn{3}{c}{$\sigma^{\circ}$} \\
Date & $\theta=0^{\circ}$ & $\theta=20^{\circ}$ & $\theta=40^{\circ}$ \\
\hline 23 June 1993 & 11.9 & -10.7 & -12.2 \\
24 June 1993 & 13.7 & -0.2 & -10.0 \\
25 June 1993 & 11.1 & 2.4 & 2.2 \\
26 June 1993 & 14.3 & 1.0 & 2.7
\end{tabular}




\section{GONGLUSION}

We have observed the details of day-to-day variability in summer melt and meltwater redistribution in the percolation zone of the Greenland ice sheet through quantitative analysis of high-resolution radar data. We found that the ice layers which form from percolation and refreezing of surface meltwater are continuous over long distances.

These observations have implications for analysis of remote-sensing data. The temporal variability in backscatter is of a magnitude that can be detected by currently operating spaceborne sensors such as the ERS-1 SAR. Because of the large temporal variability in back-scatter, the variance of time series of back-scatter coefficients should be higher in the summer than in the winter. This may be a diagnostic feature of the percolation zone and hence useful for mapping hydrologic zones using remotesensing techniques. Moreover, statistical time-series analysis of back-scatter coefficients could be used to assess and monitor the length of the summer season.

Our observations also have climatological implications. During the summer in the percolation zone the degree of surface melt varies rapidly and dramatically, but the net result of a rapidly fluctuating heat exchange between the atmosphere and the firn is a seasonally characteristic ice-layer morphology. Thus this timeintegrated response of the ice sheet which is captured in the ice layers may be diagnostic of seasonally averaged atmospheric processes. As is well known, this morphology persists through the firn as ice layers are buried from year to year. This evolution may be observable with remotesensing techniques because the near-surface radar echoes we observed are likely to represent the genesis of radioecho-sounding layers observed at great depths in the polar ice sheets. As such, the connection between atmospheric processes, the development of the physical and electrical properties of ice layers, and radio-echosounding layers observed at depth should be established. In the work reported here, we have begun to quantitatively establish links between climatological processes and the glaciological and electrical properties of ice and firn in the percolation zone.

\section{ACKNOWLEDGEMENTS}

We would like to thank $\mathrm{H}$. Brecher, E. Ferraro, M. Anderson, and C. Rowe for their assistance in pit studies. We also thank the 109th Airlift Group of the New York Air National Guard. This work is supported by the NASA Polar Oceans and Ice Sheets Program. This is BPRC contribution No. 929.

\section{REFERENCES}

Benson, C.S. 1962. Stratigraphic studies in the snow and firn of the Greenland ice sheet. SIPRE Res. Rep. 70.

Davis, C. H. and V.I. Poznyak. 1993. The depth of penetration in Antarctic firn at $10 \mathrm{GHz}$. IEEE Trans. Geosci. Remote Sensing, 31(5), $1107-1111$.

Fahnestock, M. A. and R. A. Bindschadler. 1993. Description of a program for SAR investigation of the Greenland ice sheet and an example of margin change detection using SAR. Ann. Glaciol., 17, 332-336.

Fahnestock, M., R. Bindschadler, R. Kwok and K. Jezek. 1993. Greenland ice sheet surface properties and ice dynamics from ERS-1 SAR imagery. Science, 262(5139), 1530-1534.

Ferraro, E. 1994. Analysis of airborne radar altimetry measurements of the Greenland ice sheet. (Ph.D. dissertation, University of Massachusetts, Amherst.)

Goldstein, R. M., H. Engelhardt, B. Kamb and R. M. Frolich. 1993. Satellite radar interferometry for monitoring ice sheet motion: application to an Antarctic ice stream. Science, 262 (5139), 1525-1530.

Jezek, K. C., P. Gogineni and M. Shanableh. 1994. Radar measurements of melt zones on the Greenland ice sheet. Geophys. Res. Lett., $21(1), 33-36$.

Pfeffer, W. T., M. F. Meier and T. H. Illangasekare. 1991. Retention of Greenland runoff by refreezing: implications for projected future sea level change. 7. Geophys. Res., 96 (C12), 22,117-22,124.

Rignot, E. J., S. J. Ostro, J.J. van Zyl and K. C. Jezek. 1993. Unusual radar echoes from the Greenland ice sheet. Science, 261(5129), 1710-1713.

Steffen, K., W. Abdalati and J. Stroeve. 1993. Climate sensitivity studies of the Greenland ice sheet using satellite AVHRR, SMMR, SSM/1 and in situ data. Meteorology and Atmospheric Physics, 51, 239-258.

Swift, C. T., P.S. Hayes, J.S. Herd, W. L. Jones and V.E. Delnore. 1985. Airborne microwave measurements of the southern Greenland ice sheet. J. Geophys. Res., 90(B2), 1983-1994. 